\title{
PENGARUH KUALITAS PELAYANAN TERHADAP KEPUASAAN \\ MASYARAKAT PADA PUSKESMAS KAMPUNG SAWAH KECAMATAN \\ TANJUNG KARANG TIMUR, BANDAR LAMPUNG.
}

\author{
Hendri Dunan ${ }^{1}$, Masalamah ${ }^{2}$ \\ Fakultas Ekonomi dan Bisnis, Universitas Bandar Lampung \\ Jl. ZA Pagar Alam No. 26, Labuhan Ratu, Bandar Lampung. \\ Email: hendri.dunan@ubl.ac.id; masalamah.15011055@studentubl.ac.id
}

\begin{abstract}
ABSTRAK
Tujuan dari penelitian ini adalah untuk mengetahui dan menganalisis pengaruh kualitas pelayanan terhadap kepuasan masyarakat sebagai pasien di Puskesmas Kampung Sawah Kecamatan Tanjung Karang Timur Bandar Lampung.

Populasi dalam penelitian ini adalah masyarakat yang berdomisili di wilayah kerja Puskesmas Kampung Sawah Kecamatan Tanjung Karang Timur Bandar Lampung dan telah melakukan pelayanan kesehatan di Puskesmas Kampung Sawah Kecamatan Tanjung Karang Timur Bandar Lampung dengan jumlah sampel sebanyak 100 orang Responden yang dipilih menggunakan teknik Purposive Sampling.

Pengumpulan data primer menggunakan kuesioner dan pengumpulan data sekunder menggunakan studi pustaka. Pengujian Hipotesis dalam penelitian menggunakan analisis Regresi linear berganda dengan nilai signifkan $\mathrm{a}=5 \%(0,05)$.

Hasil penelitian menunjukkan bahwa kehandalan, daya tanggap, jaminan, perhatian dan bukti fisik secara simultan berpengaruh secara positif dan signifikan terhadap kepuasan masyarakat sebagai pasien Puskesmas Kampung Sawah Kecamatan Tanjung Karang Timur Bandar Lampung.

Nilai Adjusted R Square yang didapat melalui pengujian koofesien Detereminan $\left(\mathrm{R}^{2)}\right.$ adalah sebesar 0,712 berarti menjelaskan bahwa $71,2 \%$ kepuasan masyarakat sebagai pasien sebagai variabel terikat dapat dijelaskan oleh variabel bebas, yaitu kualitas pelayanan.

Kata Kunci : kehandalan, daya tanggap, jaminan, perhatian, bukti fisik dan kepuasan masyarakat sebagai pasien.
\end{abstract}




\begin{abstract}
ABSTRAC
The purpose of this research is to determine and analyze the influence of service quality on community satisfaction as patients at the Kampung Sawah Health Center, Tanjung Karang Timur District, Bandar Lampung.

The population in this research is the community that is domiciled work area of Kampung Sawah Health Center, Tanjung Karang Timur District, Bandar Lampung and has conducted health service at the Kampung Sawah Health Center in Tanjung Karang Timur District, Bandar Lampung with the number of samples of 100 respondent selected using Purposive Sampling technique .

Primary data collection using questionnaires and secondary data collection using literature study. Hypothesis testing in this study using multiple linear regression analysis with a significant value $\mathrm{a}=$ $5 \%(0.05)$.
\end{abstract}

The results showed that the reliability, responsiveness, assurance, attention and physical evidence simultaneously influenced positively and significantly to the satisfaction of the community as a patient at the Kampung Sawah Health Center in Tanjung Karang Timur District, Bandar Lampung.

Adjusted R Squere value obtained thourgh Determinant Coofficient (R2) test is 0,712 means that $71,2 \%$ of people satisfaction patient as a dependen variable can be expalined by independent variables, namely service quality.

Keywords: reliability, responsiveness, assurance, attention, physical evidence and community satisfaction as a patient. 


\section{PENDAHULUAN}

Puskesmas Kampung Sawah Kecamatan Tanjung Karang Timur Bandar Lampung, merupakan puskesmas yang telah menerapkan Standar Pelayanan Minimal (SPM) Puskesmas yang diterbitkan oleh Departemen Kesehatan RI. Standar pelayanan orientasi kepada kepuasaan pasien/ masyarakat merupakan standar yang komprehensif bagi pelayanan kesehatan, seperti puskesmas kampung sawah. Penerapan SPM dimaksudkan untuk meningkatkan pelayan produk/jasa layanan sehingga dapat memberikan kepuasaan pelanggan.

Untuk dapat menentukan kebijakan pelayanan yang tepat, khususnya dalam pelayanan kepada pasien, diperlukan kajian tentang dimensi kualitas pelayanan terhadap pasien/masyarakat puskesmas kampung sawah, dalam hal ini pasien/masyarakat Puskesmas Kampung Sawah Kecamatan Tanjung Karang Timur Bandar Lampung. Sehubungan dengan kondisi itu, permasalahannya adalah : apakah ada pengaruh variabel realibility (kehandalan), responsiveness ( daya tanggap), ansurance (jaminan), empathy (empati), dan tangible (nyata) terhadap kepuasan pasien/masyarakat Puskesmas Kampung Sawah Kecamatan Tanjung Karang Timur Bandar Lampung.

Berdasarkan wawancara/prasurvei yang peneliti lakukan terhadap pasien/masyarakat , mengenai pelayanan di Puskesmas Kampung Sawah Kecamatan Tanjung Karang Timur Bandar Lampung terdapat persepsi dari pasien / masyarakat bahwa sebagian masih belum puas terhadap pelayanan yang diberikan. Kualitas pelayanan yang disediakan oleh Puskesmas Kampung Sawah Kecamatan Tanjung Karang Timur Bandar Lampung belum di laksanakan secara optimal. Secara umum masih terdapat kekurangan, Berdasarkan observasi awal yang peneliti lakukan kurang lebih selama 1 bulan dimana peneliti melihat langsung proses pelayanan kesehatan pada Puskesmas Kampung Sawah Kecamatan Tanjung Karang Timur Bandar Lampung. Peneliti menemukan beberapa masalah penting untuk mendukung penelitian yaitu terkait dengan : bukti nyata (tangible) yaitu masih ditemukannya pasien yang sulit parkir pada hari-hari tertentu ketika puskesmas mengadakan kegiatan puskesmas seperti posyandu, penyuluhan dan lain-lain, masih ditemukannya bungkus makanan ringan diruang tunggu yang ditinggalkan oleh pengunjung puskesmas kampung sawah. Terkait dengan kehandalan(responsivenees) proses administrasi cenderung lambat, ratarata pendataan pasien lebih dari 2 menit dikarenkan kurangnya ketenaga kerjaan di puskesmas kampung sawah,masih ditemukannya pegawai yang tidak mentaati jadwal piket,seperti datang tidak tepat waktu,sehingga pasien yang membutuhkan harus menunggu. Terkait dengan daya tanggap(responsivineess) masih ditemukannya pegawai yang masih kurang cekatan dalam menangani pasien atau belum maksimal dalam memberikan pelayanan dikarenakan kurangnya jumlah ketenaga kerja pegawai pada puskesmas kampung sawah, masih ditemukannya pegawai yang apatis dalam menanggapi keluhan pasien. Terkait dengan empati (empahty) kurangnya sifat pegawai dalam menahan emosi dan berkata kasar terhadap pasien, terkait tempat ada lahan parkir yang hingga sekarang belum diperbaiki karna terlalu sempit dan terlalu berhadapan langsung dengan jalan raya. Terkait jaminan ( ansurance) masih ditemukannya puskesmas kampung sawah yang tidak ramah, hal ini dari cara bicara pegawai yang ketus dan terlihat kasar saat melayani pasien. Tidak sesuai dengan budaya puskesmas(5S) Senyum,Salam,Sapa,Sopan dan Santun.

Pelayanan kesehatan yang diberikan kepada masyarakat oleh puskesmas ini juga penting mengingat Pusat Kesehatan masyarakat (PUSKESMAS) adalah suatu organisasi fungsional yang menyelenggarkan upaya kesehatan yang bersifat menyeluruh, terpadu, merata, dapat diterima dan terjangkau oleh masyarakat, dengan peran serta aktif masyarakat dan menggunakan hasil pengembangan ilmu pengetahuan dan teknologi tepat guna, dengan biaya yang dapat dipikul oleh pemerintah dan masyarakat.

Puskesmas Kampung Sawah Kecamatan Tanjung Karang Timur Bandar Lampung, merupakan salah satu dari sekian banyak puskesmas yang dalam pelaksanaannya ikut berpartisipasi melaksanakan pelayanan kepada masyarakat. Puskesmas Kampung Sawah Kecamatan Tanjung Karang Timur Bandar Lampung berdiri sejak tahun 2003 hingga sekarang. Puskesmas Kampung Sawah Kecamatan Tanjung Karang Timur Bandar 
Lampung mempunyai Visi yaitu : “ Menjadikan Masyarakat Kecamatan Tanjung Karang Timur Sehat Secara Mandiri”. Adapun Mottonya adalah : "Kesehatan Anda Tujuan Kami, Kepuasan Anda Kebanggan Kami”. Dan juga Misi nya Adalah :

1. Mendorong kemandirian masyarakat untuk hidup sehat.

2. Menyelenggarakan upaya kesehatan dengan mengutamakan upaya promotif dengan preventif.

3. Memelihara dan meningkatkan serta mendorong hidup sehat individu, keluarga dan masyarakat.

4. Memberikan pelayanan kesehatan

Dari uraian diatas maka peneliti mengambil judul "Pengaruh Kualitas Pelayanan Terhadap Kepuasaan Masyarakat Pada Puskesmas Kampung Sawah Kecamatan Tanjung Karang Timur Bandar Lampung”.

\section{Rumusan Masalah}

Adapun rumusan masalah dari penelitian ini adalah :

1. Apakah Tangible (Tampilan Fisik) berpengaruh terhadap kepuasaan masyarakat pada Puskesmas Kampung Sawah Kecamatan Tanjung Karang Timur Bandar Lampung?

2. Apakah Reability (Kehandalan) berpengaruh terhadap kepuasan masyarakat pada Puskesmas Kampung Sawah Kecamatan Tanjung Karang Timur Bandar Lampung?

3. Apakah Responsivenees (Daya Tanggap) berpengaruh terhadap kepuasan masyarakat pada Puskesmas Kampung Sawah Kecamatan Tanjung Karang Timur Bandar Lampung?

4. Apakah Ansurance (Jaminan) berpengaruh terhadap kepuasan masyarakat pada Puskesmas Kampung Sawah Kecamatan Tanjung Karang Timur Bandar Lampung?

5. Apakah Empaty (Kepedulian) berpengaruh terhadap kepuasan masyarakat pada Puskesmas
Kampung Sawah Kecamatan

Tanjung Karang Timur Bandar Lampung ?

\section{Tujuan Penelitian}

Adapun tujuan dari penelitian ini adalah :

1. Untuk mengetahui apakah Tangible (Tampilan Fisik) berpengaruh terhadap kepuasaan masyarakat pada Puskesmas Kampung Sawah Kecamatan Tanjung Karang Timur Bandar Lampung ?

2. Untuk mengetahui apakah Reability (Kehandalan) berpengaruh terhadap kepuasan masyarakat pada Puskesmas Kampung Sawah Kecamatan Tanjung Karang Timur Bandar Lampung?

3. Untuk mengetahui apakah Responsivenees (Daya Tanggap) berpengaruh terhadap kepuasan masyarakat pada Puskesmas Kampung Sawah Kecamatan

Tanjung Karang Timur Bandar Lampung?

4. Untuk mengetahui apakah Ansurance (Jaminan) berpengaruh terhadap kepuasan masyarakat pada Puskesmas Kampung Sawah Kecamatan Tanjung Karang Timur Bandar Lampung?

5. Untuk mengetahui apakah Empaty (Kepedulian) berpengaruh terhadap kepuasan masyarakat pada Puskesmas Kampung Sawah Kecamatan Tanjung Karang Timur Bandar Lampung?

\section{TINJAUAN PUSTAKA, KERANGKA KONSEPTUAL DAN HIPOTESIS}

Menurut Moenir HAS (2006:8). Pengertian manajemen pelayanan publik/umum adalah manajemen proses yang kegiatannya diarahkan secara khusus pada terselenggaranya pelayanan guna memenuhi keinginan umum/kepentingan perorangan,memulai caracara yang tepat dan memuaskan pihak yang dilayani.

Menurut Mauludin (2013:67) mengemukakan bahwa kualitas pelayanan adalah seberapa jauh perbedaan antara kenyataan dan harapan 
pelanggan atas layanan yang mereka terima atau peroleh.

Menurut Kotler dan Keller yang dikutip oleh Bob Sabran (2012:177) kepuasan konsumen adalah merupakan perasaan senang atau kecewa seseorang yang muncul setelah membandingkan antara kinerja atau hasil yang diharapkanya. Fandy Tjiptono (2012:146) kepuasan pelanggan adalah perasaan senang atau kecewa seseorang yang muncul setelah membandingkan antara persepsi terhadap kinerja (hasil) suatu produk dengan harapanharapanya.

Kerangka Konseptual

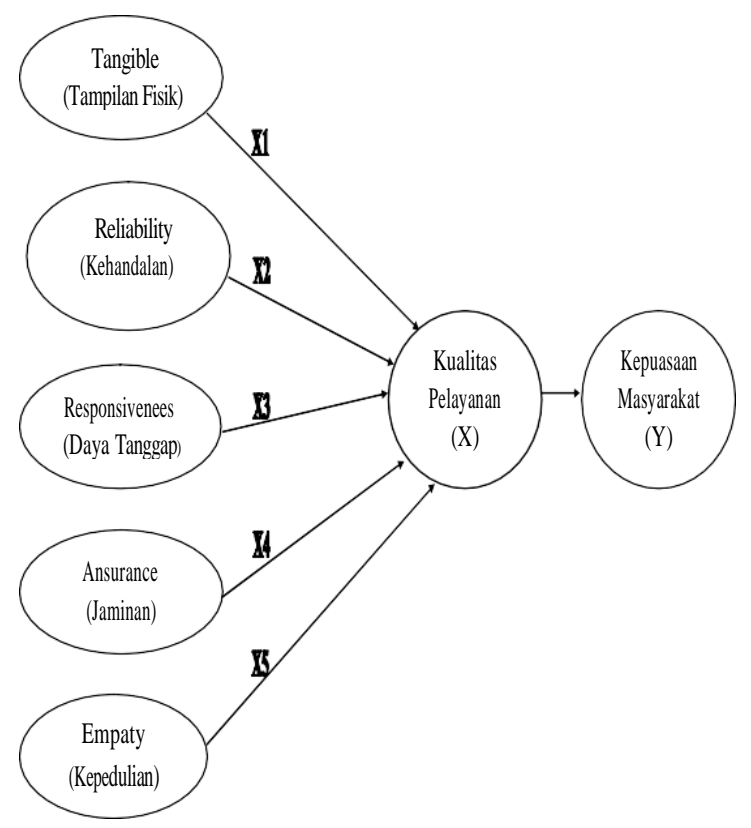

\section{Hipotesis}

Sugiono (2017:63) menyatakan bahwa hipotesis merupakan jawaban sementara terhadap rumusan masalah penelitian, dimana rumusan masalah dinyatakan dalam bentuk kalimat pertanyaan.

Berdasarkan uraian latar belakang, rumusan masalah, tujuan peneltian dan kerangka konseptual, maka hipotesis yang diajukan dalam penelitian ini adalah Tangible (Bukti Fisik) , Reliability (Kehandalan), Responsivenees (Daya Tanggap), Ansurane (Jaminan), Empaty (Kepedulian) berpengaruh positif dan signifikan terhadap kepuasan masyarakat pada Puskesmas Kampung Sawah Kecamatan Tanjung Karang Timur Bandar Lampung.

\section{Desain Penelitian}

Definisi desain penelitian menurut (Moh.Nazir 2008:1) adalah semua proses yang diperlukan dalam perencanaan dan pelaksanaan penelitian, mulai tahap persiapan sampai tahap penyusunan laporan. Desain penelitian yang digunakan dalam penelitian ini adalah Deskriptif Regresif dengan tujuan untul memecahkan atau menjawab permasalahan yang diteliti yaitu Kualitas Pelayanan Terhadap Kepuasan Masyarakat pada Puskesmas Kampung Sawah Kecamatan Tanjung Karang Timur Bandar Lampung berdasarkan teori-teori yang terdapat pada bab dua.

\section{Metode Analisis}

\section{Analisis Data Kualitatif}

Yaitu analisis dimana data yang diperoleh mengenai objek penelitian yang merupakan data kualitatif dianalisisis berdasarkan perbandingan teori dari literatur dengan kenyataan yang diperoleh penulis selama peneltian dilakukan. Dengan metode penelitian yaitu deskriptif untuk melihat atau menggambarkan bagaimana pengaruh kualitas pelayanan dalam upaya mewujudkan pengaruh yang positif kepada masyarakat yang menggunakan ayanan pada Puskesmas Kecamatan Tanjung Karang Timur Bandar Lampung.

\section{Analisis Data Kuantitatif}

Yaitu dengan melakukan pengolahan data dengan menggunakan rumus-rumus atau metode statistik untuk mempermudah analisisis data maka dalam penelitian ini menggunakan Software Spss 18.

\section{ANALSIS DATA DAN PEMBAHASAN}

\section{Analisis Regresi Linear Berganda}

Analisis regresi linear berganda digunakan dalam penelitian ini dengan tujuan untuk mengetahui ada tidaknya pengaruh variabel bebas terhadap variabel terikat.

Perhitungan statistik dalam analisis regresi linier berganda yaitu dengan menggunakan bantuan program komputer SPSS for Windows versi 17. Hasil pengolahan data dengan menggunakan program SPSS selengkapnya ada pada lampiran dan selanjutnya dijelaskan pada Tabel 4.10 berikut ini : 
Tabel 4.10

Hasil Analisis Regresi Linier Berganda cutlitiants'

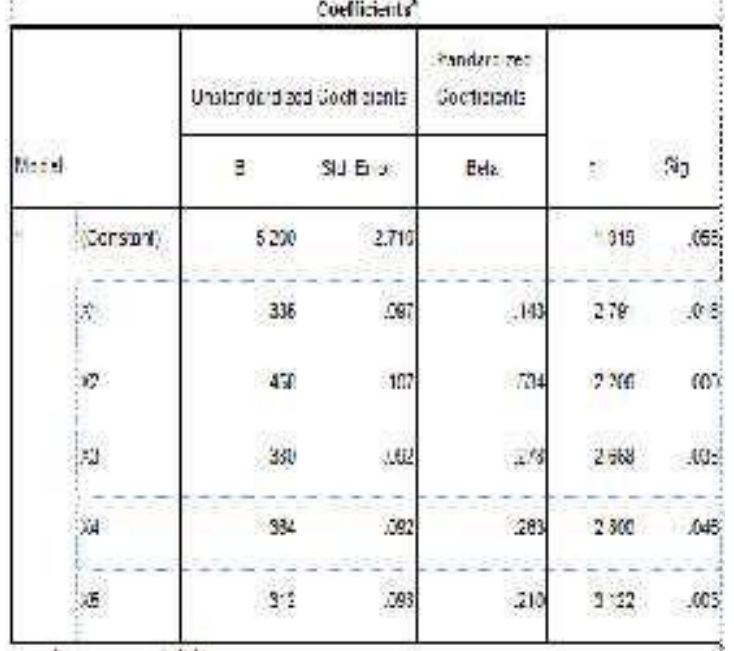

Sumber : Data Diolah, 2019

Dari tabel 4.10 di atas dapat dibuat persamaan regresi berganda sebagai berikut :

$$
\begin{gathered}
Y=5.200+0,335 X_{1}+0,458 X_{2}+0,380 X_{3}+ \\
0,364 X_{4}+0,312 X_{5}+e_{t}
\end{gathered}
$$

Keterangan :

$\mathbf{Y}=$ Kepuasan Konsumen

$\mathbf{X 1}=$ Tangible (Bukti Fisik)

$\mathbf{X} \mathbf{2}=$ Reliability (Keandalan)

$\mathbf{X 3}=$ Responsiveness (Ketanggapan)

$\mathbf{X} \mathbf{4}=$ Assurance $($ Jaminan/Kepastian $)$

X5 = Emphaty (Empati)

$\mathbf{e}_{\mathrm{t}}=$ Error

\section{Interpretasi:}

Dari hasil persamaan regresi linear seperti diatas, maka dapat diberikan interpretasi sebagai berikut:

1) Nilai konstanta (a) sebesar 5.200 mengandung arti bahwa jika tidak memperhatikan Tangible (Bukti Fisik), Reliability (Keandalan), Responsiveness (Ketanggapan),

Assurance

(Jaminan/Kepastian), dan Emphaty (Empati) maka Kepuasan Konsumen hanya sebesar 8.404.

2) Koefisien regresi $X 1$ yaitu sebesar 0,335 , hal ini menunjukkan bahwa kontribusi Tangible (Bukti Fisik) terhadap Kepuasan Konsumen sebesar 0,335, atau apabila Tangible (Bukti Fisik) meningkat sebesar 1 point, maka Kepuasan Konsumen akan meningkat 0,335 point pada konstanta 5.200 .

3) Koefisien regresi $\mathrm{X} 2$ yaitu sebesar 0,458 , hal ini menunjukkan bahwa kontribusi Reliability (Keandalan) terhadap Kepuasan Konsumen sebesar 0,458, atau apabila Reliability (Keandalan) meningkat sebesar 1 point, maka Kepuasan Konsumen akan meningkat 0,458 point pada konstanta 5.200.

4) Koefisien regresi $X 3$ yaitu sebesar 0,380, hal ini menunjukkan bahwa kontribusi Responsiveness (Ketanggapan) terhadap Kepuasan Konsumen sebesar 0,380, atau apabila Responsiveness (Ketanggapan) meningkat sebesar 1 point, maka Kepuasan Konsumen akan meningkat 0,380 point pada konstanta 5.200.

5) Koefisien regresi X4 yaitu sebesar 0,364, hal ini menunjukkan bahwa kontribusi Assurance (Jaminan/Kepastian) terhadap Kepuasan Konsumen sebesar 0,364, atau apabila Assurance (Jaminan/Kepastian) meningkat sebesar 1 point, maka Kepuasan Konsumen akan menurun 0,364 point pada konstanta 5.200 .

6) Koefisien regresi X5 yaitu sebesar 0,312, hal ini menunjukkan bahwa kontribusi Emphaty (Empati) terhadap Kepuasan Konsumen sebesar 0,312, atau apabila Emphaty (Empati) meningkat sebesar 1 point, maka Kepuasan Konsumen akan meningkat 0,312 point pada konstanta 5.200 .

7) Yang paling besar berpengaruh terhadap kinerja Karyawan adalah Reliability (Keandalan) yaitu sebesar 0,458.

\section{Uji Hipotesis}

Uji Signifikansi parameter individual (Uji Statistik t)

Untuk menguji keberartian model regresi untuk masing-masing variabel dapat diperoleh dengan menggunakan uji t. Berikut akan dijelaskanpengujian masing-masing variabel.

Tabel 4.11

\begin{tabular}{|c|c|c|c|c|}
\hline Peтgun & $r_{\text {in: }}$ & $t_{3 x} x^{01} \leq u(y)$ & Emalisi & Fesimpnlan \\
\hline 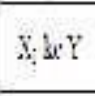 & 2.291 & 1586 & 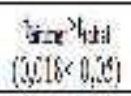 & 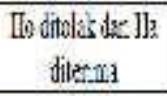 \\
\hline Ait & 2006 & 1586 & 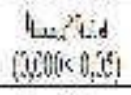 & 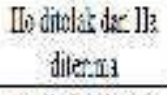 \\
\hline A bey & Sifto & $1,9, \mathrm{fi}$ & 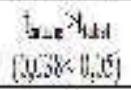 & $\begin{array}{c}\text { Ho ditoles ite } \mathrm{Hz} \\
\text { ditoral }\end{array}$ \\
\hline Xkey & Sini & 1,536 & $\begin{array}{l}\text { Lexided } \\
{[1,-40 ; 0,5]}\end{array}$ & $\begin{array}{c}\text { He dilexzes dill } \\
\text { Hediuls }\end{array}$ \\
\hline WheY & $: 12$ & 1,936i: & 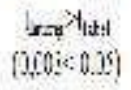 & $\begin{array}{l}\text { Ho ditula de H. } \\
\text { filtenes }\end{array}$ \\
\hline
\end{tabular}

Hasil Analisis Uji t

(Sumber: Data primer diolah, 2019) 
1. Tangible (Bukti Fisik) terhadap Kepuasan Konsumen (Y)

Untuk variabel kepercayaan diperoleh nilai $t_{\text {hitung }}$ sebesar 2.791 lebih besar dari nilai $t_{\text {tabel }} 1,986$ atau dengan kata lain $t_{\text {hitung }}>t_{t a b e l}$, sedangkan hasil significant yang diperoleh sebesar 0,018 , lebih kecil dari $\alpha$ yang ditentukan yaitu 0,05 sehingga dapat dikatakan significant. Dengan demikian, Ho ditolak dan Ha diterima, atau dengan kata lain:

Hipotesis pertama: Tangible (Bukti Fisik) berpengaruh signifikan Kepuasan Konsumen pada Puskesmas Kampung Sawah Kecamatan Tanjung Karang Timur Bandar Lampung.

2. Reliability (Keandalan) terhadap Kepuasan Konsumen (Y)

Untuk variabel kepercayaan diperoleh nilai $t_{\text {hitung }}$ sebesar 2.206 lebih besar dari nilai $\mathrm{t}_{\text {tabel }} 1,986$ atau dengan kata lain $t_{\text {hitung }}>t_{\text {tabel }}$, sedangkan hasil significant yang diperoleh sebesar 0,000, lebih kecil dari $\alpha$ yang ditentukan yaitu 0,05 sehingga dapat dikatakan significant. Dengan demikian, Ho ditolak dan $\mathrm{Ha}$ diterima, atau dengan kata lain:

Hipotesis kedua: Reliability (Keandalan) berpengaruh signifikan Kepuasan Konsumen pada Puskesmas Kampung Sawah Kecamatan Tanjung Karang Timur Bandar Lampung.

3. Responsiveness (Ketanggapan) terhadap Kepuasan Konsumen (Y)

Untuk variabel kepercayaan diperoleh nilai $t_{\text {hitung }}$ sebesar 2.668 lebih besar dari nilai $t_{\text {tabel }} 1,986$ atau dengan kata lain $t_{\text {hitung }}>t_{\text {tabel}}$, sedangkan hasil significant yang diperoleh sebesar 0,038 , lebih kecil dari $\alpha$ yang ditentukan yaitu 0,05 sehingga dapat dikatakan significant. Dengan demikian, Ho ditolak dan Ha diterima, atau dengan kata lain:

Hipotesis ketiga: Responsiveness (Ketanggapan) berpengaruh signifikan Kepuasan Konsumen pada Puskesmas Kampung Sawah Kecamatan Tanjung Karang Timur Bandar Lampung.

4. Assurance (Jaminan/Kepastian) terhadap Kepuasan Konsumen (Y)

Untuk variabel kepercayaan diperoleh nilai $t_{\text {hitung }}$ sebesar 2.800 lebih besar dari nilai $t_{\text {tabel }}$ 1,986 atau dengan kata lain $\mathrm{t}_{\text {hitung }}>\mathrm{t}_{\text {tabel }}$, sedangkan hasil significant yang diperoleh sebesar 0,046 , lebih kecil dari $\alpha$ yang ditentukan yaitu 0,05 sehingga dapat dikatakan significant. Dengan demikian, Ho ditolak dan $\mathrm{Ha}$ diterima, atau dengan kata lain:

Hipotesis keempat: Assurance (Jaminan/Kepastian) berpengaruh signifikan Kepuasan Konsumen pada Puskesmas Kampung Sawah Kecamatan Tanjung Karang Timur Bandar Lampung.

5. Emphaty (Empati) terhadap Kepuasan Konsumen (Y)

Untuk variabel kepercayaan diperoleh nilai thitung sebesar 3.122 lebih besar dari nilai $t_{\text {tabel }} 1,986$ atau dengan kata lain $t_{\text {hitung }}>t_{\text {tabel }}$, sedangkan hasil significant yang diperoleh sebesar 0,003 , lebih kecil dari $\alpha$ yang ditentukan yaitu 0,05 sehingga dapat dikatakan significant. Dengan demikian, Ho ditolak dan $\mathrm{Ha}$ diterima, atau dengan kata lain:

Hipotesis kelima: Emphaty (Empati) berpengaruh signifikan Kepuasan Konsumen pada Puskesmas Kampung Sawah Kecamatan Tanjung Karang Timur Bandar Lampung.

Uji Signifikansi Simultan (Uji Statistik F)

Hasil perhitungan regresi secara simultan diperoleh pada Tabel 4.12 berikut ini :

Tabel 4.12

Hasil Analisis Regresi Secara BersamaSama

AMOug?

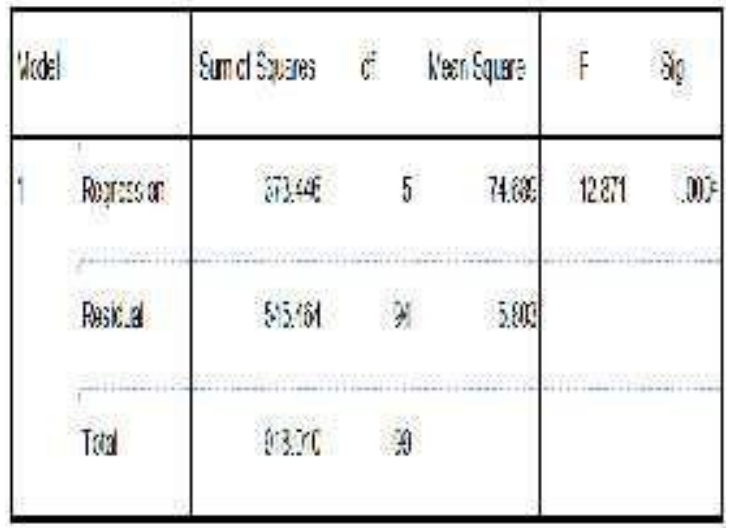

(Sumber : Dataprimer diolah, 2019)

A. Predictors: (Constant), Empathy (Empati) ,Reliability (keandalan), Responsiveness (ketanggapan), Tangibles (buktifisik) Assurance (jaminan/kepastian)

b. Dependent Variable : Kepuasan Konsumen 
Untuk pengujian secara simultan diperoleh nilai $F_{\text {hitung }}(12.871)>F_{\text {tabel }}(2,31)$ dengan nilai signifikansi (sig.) $0,000<\alpha 0,05$, sehingga Ho ditolak dan Ha diterima yang berarti secara bersama-sama Tangible (Bukti Fisik)(X1), Reliability (Keandalan) (X2), Responsiveness (Ketanggapan) (X3), Assurance (Jaminan/Kepastian) (X4), dan Emphaty (Empati)(X5) berpengaruh signifikan terhadap Kepuasan Konsumen (Y) pada Puskesmas Kampung Sawah Kecamatan Tanjung Karang Timur Bandar Lampung.

\section{Koefisien Determinasi}

Tabel 4.13

Koefesien Determinasi

\begin{tabular}{|c|c|c|c|c|}
\hline \multicolumn{5}{|c|}{ Model Summary } \\
\hline Mode & R & R Square: & $\begin{array}{l}\text { Aqusted } R \\
\text { Square }\end{array}$ & $\begin{array}{l}\text { Stad Error of he } \\
\text { Estimate }\end{array}$ \\
\hline 1 & $875^{\circ}$ & 712 & 691 & 4.229 \\
\hline \multicolumn{5}{|c|}{$\begin{array}{l}\text { a. Predictors: (Constant), Enpathy (Empati), Relinbility } \\
\text { (keandahn), Resporsiveness (ketanggrpan), Tanghiles } \\
\text { (oukti fisk), Assurance (jammankepastian) }\end{array}$} \\
\hline
\end{tabular}

Sumber: Data Diolah dengan SPSS 17, 2019

Dari tabel di atas memperlihatkan keeratan pengaruh variabel Kualitas Pelayanan terhadap Kepuasan Konsumen. Hasil perhitungan diperoleh $R=0,875$ dan koefisien determinasi sebesar $\mathrm{R}^{2}=0,712$ atau $71,2 \%$. Besarnya koefisien determinasi, memberikan arti bahwa besarnya perubahan pada variabel Kepuasan Konsumen 71,2\% dipengaruhi oleh Kualitas Pelayanan, sedangkan sisanya $28,8 \%$ dipengaruhi oleh faktor lain yang tidak penulis teliti seperti Kualitas Produk, Promosi, Loyalitas Konsumen, Tempat dan lain-lain.

\section{KESIMPULAN DAN SARAN \\ Kesimpulan}

Berdasarkan penelitian tentang pengaruh Kualitas Pelayanan terhadap Kepuasan Masyarakat pada Puskesmas Kampung Sawah Kecamatan Tanjung Karang Timur Bandar Lampung, maka diperoleh kesimpulan sebagai berikut:

1. Tangibles (bukti fisik) berpengaruh positif dan signifikan terhadap kepuasan masyarakat pada Puskesmas
Kampung Sawah Kecamatan Tanjung Karang Timur Bandar Lampung.

2. Reliability (keandalan) berpengaruh positif dan signifikan terhadap kepuasan masyarakat pada Puskesmas Kampung Sawah Kecamatan Tanjung Karang Timur Bandar Lampung.

3. Responsiveness (ketanggapan) berpengaruh positif dan signifikan terhadap kepuasan masyarakat pada Puskesmas Kampung Sawah Kecamatan Tanjung Karang Timur Bandar Lampung.

4. Assurance (jaminan/kepastian) berpengaruh positif dan signifikan terhadap kepuasan masyarakat pada Puskesmas Kampung Sawah Kecamatan Tanjung Karang Timur Bandar Lampung.

5. Empathy (Empati) berpengaruh positif dan signifikan terhadap kepuasan masyarakat pada Puskesmas Kampung Sawah Kecamatan Tanjung Karang Timur Bandar Lampung.

6. Tangibles (bukti fisik), Reliability (keandalan), Responsiveness (ketanggapan) dan Assurance (jaminan/kepastian) serta Empathy (Empati) secara bersama-sama berpengaruh positif dan signifikan terhadap kepuasan masyarakat pada Puskesmas Kampung Sawah Kecamatan Tanjung Karang Timur Bandar Lampung.

\section{Saran}

Berdasarkan kesimpulan yang telah dikemukakan, maka diberikan beberapa saran yang diharapkan dapat meningkatkan Kepuasan Masyarakat pada Puskesmas Kampung Sawah Kecamatan Tanjung Karang Timur Bandar Lampung. Adapun saran-saran yang diberikan bagi perusahaan adalah sebagai berikut:

1. Sebaiknya Puskesmas Kampung Sawah Kecamatan Tanjung Karang Timur Bandar Lampung meningkatkan lahan parkir kendaraan agar tersedia banyak dan tidak memungut biaya parkir

2. Sebaiknya Puskesmas Kampung Sawah Kecamatan Tanjung Karang Timur Bandar Lampung meningkatkan pelaksanaan jam kerja agar tepat waktu. 
3. Sebaiknya Puskesmas Kampung Sawah Kecamatan Tanjung Karang Timur Bandar Lampung meningkatkan kinerja karyawan serta terampil dalam bidang tugasnya

4. Sebaiknya Puskesmas Kampung Sawah Kecamatan Tanjung Karang Timur Bandar Lampung meningkatkan kinerja karyawan agar memberikan pelayanan secara menyeluruh dan tuntas.

5. Sebaiknya Puskesmas Kampung Sawah Kecamatan Tanjung Karang Timur Bandar Lampung memberikan ganti rugi jika masyarakat merasa tidak puas dengan kesalahan yang dilakukan oleh Puskesmas Kampung Sawah Kecamatan Tanjung Karang Timur.

6. Sebaiknya Puskesmas Kampung Sawah Kecamatan Tanjung Karang Timur Bandar Lampung menjaga jaminan mutu kualitas pelayanan kepada konsumen agar kepuasan masyarakat Puskesmas Kampung Sawah Kecamatan Tanjung Karang Timur Bandar Lampung dapat meningkat lebih baik lagi.

\section{DAFTAR PUSTAKA}

Appley A, Lawrence dan Lee, Oey Ling 2010.

"Pengantar Manajemen"

https://www.google.co.id/search?q=m anajemen+Menurut+Appley+dan+Oey +Liang (Diakses 07 November 2018).

Atik Septi Winarsih

\section{"Standar Pelayanan Publik", "Prinsip Pelayanan Publik" (Kepmenpan Nomor 63 Tahun 2004), Yogyakarta : Universitas Yogyakarta.}

G.R. Terry dan Hasibuan 2011 Pengantar Manajemen "

https://www.google.co.id/search?q=m anajemen+menurut+G.R.Terry+dalam +Hasibuan chrome\&ie=UTF-8 (Diakses 07 November 2018).

Kotler dan Keller yang dikutip oleh Bob Sabran 2012. “Pengertian Kepuasan Konsumen https://www.google.co.id/search?safe= strict\&ei=CPkJXOiAE8rwvgSNspTo Dw\&q=pengertian+kepuasan+menuru t+Jiptono+dan+Candra+2012\&oq. (Diakses 09 November 2018).
Kotler Zulian Yamit, 2005. ”Mengukur

Kepuasaan Konsumen ".

https://www.google.co.id/search?q=m engukur+kepuasan+pelanggan+Kotler +Zulichrome\&ie=UTF-8 (Diakses 09 November 2018).

Margono, 2004: 126 http://www.pengertianku.net/2015/03/ pengertian-populasi-dan-sampel-sertateknik-sampling random.html (diakses 10 Desember 2018).

Parasuraman, Zeithaml, dan Berry dalam Tjiptono 2011. “ Dimensi Kualitas Pelayanan ". https://www.google.co.id/search?q=di mensi+kualitas+pelayanan+menurut+ Menurut+Parasuraman $\% 2 \mathrm{C}+$ Zeithaml $\% 2 \mathrm{C}+$ dan+Berry+dalam+Tjiptono+ $(2$ 011\%3A174-175 =chrome\&ie=UTF-8 (Diakses 07 November 2018).

Sugiyono 2011, Rumus solvin https://www.google.co.id/search?safe= strict\&ei=4gQKXOzpC5i99QPG77qQ Dw\&q=rumus + solvin\%2C+Menurut+ Sugiyono+\%28+2011\%3A62\%29+yai tu+\%3A\&oq=rumus+solvin (Diakses 07 November 2018).

Sugiyono 2009. " Skala Likert “. (https://www.google.co.id/search?safe $=$ strict\&ei=HAQKXJraFZa6vwSe_YK wCg\&q=skala+likert+menurut+Sugiy ono+\%282009\%3A134\%29+\&oq=ska la+likert+menurut+Sugiyono. (Diakses 17 November 2018).

Sugiono, 2014 Definisi Sampel dan Populasi. https://www.google.co.id/search?safe= strict\&ei $=\mathrm{CgYKXNvAO4XUvgTuspi}$ oCA\&q=populasi + dan + sample $+\% 28 \mathrm{~S}$ ugiono\%2C+2014\%3A80\&oq=popula si+dan+sample+\%28Sugiono(Diakses 07 November 2018).

Zein 2009 dan Mahmoedin 2010 "Definisi Pelayanan"

http://semuapengertian31.blogspot.co $\mathrm{m} / 2016 / 04 /$ pengertian-pelayanan-dankualitas.html (Diakses 07 November 2018). 